\title{
Initial adhesion of Listeria monocytogenes to solid surfaces under liquid flow
}

Szlavik, Julie; Soares Paiva, Dionísio; Mørk, Nils; van der Berg, Franciscus Winfried J; Whitehead, Kathryn; Arneborg, Nils; Knøchel, Susanne; Nielsen, Dennis Sandris

Publication date:

2011

Document version

Også kaldet Forlagets PDF

Citation for published version (APA):

Szlavik, J., Soares Paiva, D., Mørk, N., van der Berg, F. W. J., Whitehead, K., Arneborg, N., Knøchel, S., \& Nielsen, D. S. (2011). Initial adhesion of Listeria monocytogenes to solid surfaces under liquid flow. Abstract fra 9th Symposium on Food Microbiology, Helsingør, Danmark. 
FOOD

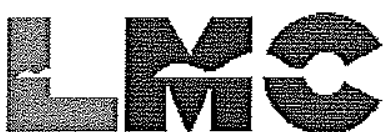

\section{Microbiology}

NeTWORK

\section{9th Symposium on Food Microbiology \\ May 12-13 2011 \\ Konventium (LO skolen), Helsingør}

The LMC Food Microbiology Network was established in 2003 in order to initiate new and intensify existing collaborations between researchers working on food microbiology within LMC. One of the means by which to achieve this is through a yearly meeting in May/June. The primary activities within the LMC Food Microbiology Network include collaborations between:

- Division of Microbiology and Risk Assessment, National Food Institute, DTU (Coordinator)

- Division of Food Production Engineering, National Food Institute, DTU

- Center for Systems Microbiology, Institute for Systems Biology, DTU

- Department of Veterinary Disease Biology, Faculty of Life Sciences, KU

- Food Microbiology, Department of Food Science, Faculty of Life Sciences, KU

- Molecular Microbial Ecology Group, Department of Biology, KU.

- Department of Biochemistry and Molecular Biology, ,University of Southern Denmark.

- Department of Food Science, University of Aarhus. 
FOOD

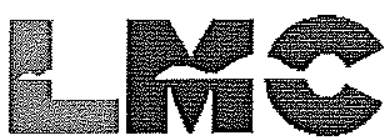

\section{Microbiology}

\section{Network}

\section{Program}

Thursday May $12^{\text {th }}$

$0930-1000$ Registration (coffee)

$1000 \quad$ Welcome by organizer

(Lars B. Jensen)

Session I: Phages

Chair Mogens Kilstrup and Lars B. Jensen

$1035 \quad$ Lone Brønsted

KU-Life Identification of a novel receptor of phages infecting Campylobacter jejuni

1100 Witold Kot KU-Life Sequence and comparative analysis of Leuconostoc dairy bacteriophages

$1120 \quad$ Peter Kjelgaard

KU-Life Mutations interfering with mobilization of prophages and pathogenicity islands

11 40- 1200 Break

Session II Antimicrobial compounds

Chair: Lars B. Jensen and Nete Bernbom

1200

Gitte Knudsen

DTU

Sub-lethal concentrations of antibiotics affect gene expression and physiology of Listeria monocytogenes

1220

Line E. Thomsen

KU-Life

Peptoid inhibits essential cellular functions through unspecific binding to DNA in S. aureus

1240

Ellen G. Christensen

DTU Triclosan exposure induce aminoglycoside resistance in Listeria monocytogenes

$1300-1400$ Lunch

Session Il: Production and processing

Chair : Søren Aabo and Marianne Halberg Larsen

1400

Krist Gernaey

DTU

Jan Martinussen

DTU

1430

Jakob Vang Rytter

DTU

Linking population heterogeneity to fermentatior mechanistic modeling approach

1500

Cleide O.A. Møller

DTU

1520

Cleide O.A. Møller

$\mathrm{Chr}$

Lactic Acid Bacteria as a new platform for sustain: biochemicals - challenges and opportunities

Thomas Janzen

Chr. Redirecting carbon fluxes in Corynebacterium glutamicum Modelling transfer of Salmonella DT104 during the grinding of pork S. thermophilus to avoid floating curd during cottage cheese production 
Poster flashes

$1615 \quad$ Katrine Joensen

1620

Finn K. Vogensen

1625

1630

1635

1640

1645

1650

1655

Tine Rask Licht

Cecilie Marvig Nielsen

Cisse Hedegaard Porsby

Marianne Kirstine Kjeldsen

Paw Dalgaard

Per Sand Roshaug

Sidsel Henriksen

$1700-1830$ Poster session and drinks

1900

Dinner

Friday May $13^{\text {th }}$

$800-900$ Breakfast
SSI Detection of a New bacteriophage among Salmonella outbreak isolates

KU-Life Analysis of lactococcal 936 phage population at a dairy by quantitative PCR and PCR-DGGE.

KU-Life Heat tolerance of dairy lactococcal c2 phages DTU Effect of tropodithietic acid on gene expression in Salmonella Typhimurium

SSI Development of a multiple-locus variable number tandem repeat analysis for subtyping of Salmonella Dublin DTU Pasta Salad Predictor-development of a new tool to support shelf-life and safety management

KU-Life Predictive model of Listeria monocytogenes.

DTU The impact of commercially available starter cultures on virulence properties of Salmonella Typhimurium in in-vitro cell culture assays and gene expression studies

DTU Effects of putatively prebiotic carbohydrates on pathogenic infections

Session VI: Intestinal microbiology

Chair: Tine R Licht+ Dennis Sandris Nielsen

Abstract missing approach to the study of the instestinal 
microbial system

1000

Tine Ebersbach

DTU

DTU

Mathilde B. Kristensen

Anne Holch

DTU
Metagenomic sequencing of the faecal microbiota of gunea pigs fed with probiotics

The complexity of the murine microbiota Influences recruitment of immune cells in early life

Listeria monocytogenes strains encoding inlA with premature stop codons are able to infect pregnant mice

1100-11 15 Break

Session V: Biofilm and adhesion

Chair: Paw Dalgaard and Susanne Knøchel

Tim Tolker-Nielsen

Nete Bernbom

DTU

1145

1205

Julie Szavik

KU-Life

Panum of Pseudomonas aeruginosa biofilms The effect of marine bacterial biofilms on attachment of common microbial biofoulers

Initial adhesion of Listeria monocytogenes to solid surfaces under liquid flow

$1225 \quad$ Closing of the symposium

$1230 \quad$ Lunch 


\section{Initial adhesion of Listeria monocytogenes to solid surfaces under liquid flow}

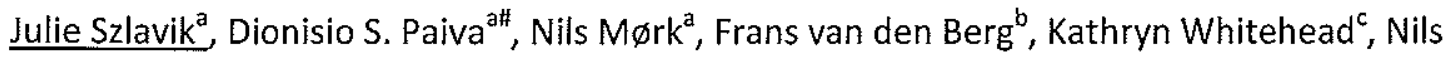
Arneborg $^{a}$, Susanne Knøchel ${ }^{a}$, Dennis S. Nielsen ${ }^{\text {a }}$

a Department of Food Science, Food Microbiology, Center for Advanced Food Studies (LMC), Faculty of Life Sciences, University of Copenhagen, Denmark

${ }^{b}$ Department of Food Science, Quality \& Technology, Center for Advanced Food Studies (LMC), Faculty of Life Sciences, University of Copenhagen, Denmark

"Department of Biology, Manchester Metropolitan University, England

"Present affiliation: Center for Systems Biology, Technical University of Denmark

It has been found that some strains of the food borne pathogen Listeria monocytogenes have a higher tendency to persist in food processing environments than other strains. The exact reason behind this phenomenon is not known, but strain differences in the ability to adhere to solid surfaces could offer an explanation. In the present work, the initial adhesion of nine strains of $L$. monocytogenes was investigated under liquid flow at two levels of shear stress on six different surfaces using a flow chamber set-up and microscopy. The surfaces tested were glass and PVC as well as glass coated with beef extract, casein, homogenized, and unhomogenized milk to elucidate strain differences and the importance of surface soiling in food production equipment on initial adhesion. In addition the effect of environmental stress ( $\mathrm{NaCl}$ and low nutrient availability) on initial adhesion was investigated. The hydrophobicity of the investigated surfaces was determined by contact angle measurements and the surface properties of the investigated $L$. monocytogenes strains were determined using MATS. Strain differences were found to significantly influence initial adhesion rate $(I A R)$ of all nine strains to all the surfaces $(P<0.05)$ at both low and high shear stress. Further there was a significant effect of the surfaces tested $(P<$ 0.05 ) in the adhesion ability of almost all strains. The IAR was affected by flow rate (shear stress) seen by a decrease in adhesion at high shear stress. All surfaces were highly hydrophobic and there was no correlation between surface hydrophobicity and IAR. There was a decrease in IAR when the cells were propagated in TSB with $5 \% \mathrm{NaCl}$ compared to TSB without $\mathrm{NaCl}$ and an increase when propagated in low nutrient media (10\% TSB). These results indicate that there are large differences in initial adhesion properties between different strains of $L$. monocytogenes under liquid flow, but no clear correlation behind IAR and persistence was found. Further studies are needed to elucidate the mechanisms behind these observations. 